\title{
INTELLIGENT HIERARCHIZATION OF SERVICE ELEMENTS CONTRIBUTING TO OVERALL CUSTOMER SATISFACTION "CASE OF AIR ALGERIE CUSTOMERS”
}

\author{
Djamila Chikh Kadri \\ Abou Bakr Belkaid University, Tlemcen, Algeria \\ kadri_djam@yahoo.fr \\ Djazia Amina Chib \\ Abou Bakr Belkaid University, Tlemcen, Algeria \\ djazia.chib@univ-tlemcen.dz \\ Assia Brahimi \\ Higher school of management, Tlemcen, Algeria \\ bra.assia@gmail.com
}

\begin{abstract}
The present work is part of relational marketing, in particular consumer behavior in the field of service. Relationship marketing is based mainly on three pillars: quality, satisfaction, and loyalty.

The choice of our conceptual model is based on an in-depth literature of previous studies, in view of the multiplicity of research work carried out in this field and the diversity of points of view of the researchers. The fundamental research question is: How to increase the level of customer satisfaction to retain them? The objective of this article is both to determine the explanatory dimensions of consumer satisfaction, but also to analyze their influence on overall consumer satisfaction. For this purpose, we have opted for the "FILTER" type attribute selection methods based on the "WEKA" programming environment. To this end, an empirical study was carried out. We employed quantitative methodology and data were analyzed by Structural Equation Models. The sample consisted of 242 customers of the airline "AIR ALGERIE". The results obtained reveal to us what is hidden behind the overall customer satisfaction of this company. They also certify that the dimensions in question contribute differently to this satisfaction. Such results would help leaders to provide a double effort in order to bring real and effective improvements, but also to give more care to the relevant variables selected by the different methods applied. However, the results also revealed the importance of the service elements which contribute to overall customer satisfaction.
\end{abstract}

Keywords: Overall Satisfaction, Elements of Service, Prioritization, Attribute Selection Methods.

DOI: https://doi.org/10.24818/beman/2021.11.1-04 


\section{INTELLIGENT HIERARCHIZATION OF SERVICE ELEMENTS CONTRIBUTING TO OVERALL CUSTOMER SATISFACTION “ CASE OF AIR ALGERIE CUSTOMERS "}

\section{INTRODUCTION}

Marketing has gone through a phase of strategic reorientation. The basis for this change is the shift from 'product orientation' to 'relationship (customer) orientation'. The interest of marketing has never evolved as much as in recent years. In the past, traditional marketing had mainly focused on acquiring new customers nowadays; the importance and value of the relationship with customers are undoubtedly the drivers of any business strategy, whose goal is to operate successfully in an increasingly hostile environment, companies are expected to develop defensible competitive advantages. In this regard, this passage is necessary and involves a series of changes in the way of approaching a client.

Being interested in the field of customer satisfaction means moving towards relationship marketing which is mainly based on creating and maintaining a lasting relationship between the company and the customer. The persistence of this relationship cannot be done without the latter feeling satisfied and delighted. Customer satisfaction is a major issue for any business, it appears as a key concept in management science, especially in relationship marketing. Its central role is illustrated in business strategy and in academic literature (Honomichl, 1993; Keith, 1960; Mittal and Kamakura, 2001; Popescu et al., 2017). The concept of "customer satisfaction" has been adopted in several fields of research, such as education (student satisfaction) health sciences (patient satisfaction) and psychology (satisfaction with life, couple, their social relations...). For companies and in their ultra-competitive environments, customer satisfaction is the key to success, the raison of being and the condition for their sustainability. Indeed, no one can imagine a business without customers. No branch of activity escapes the notion of "customer" whether its products are tangible or intangible. Therefore, managers are committed on a daily basis to both ensure and develop the satisfaction of their customers by listening to them and anticipating their requests.

Our study raises the problem of customer satisfaction of the airline "AIR ALGERIE" by identifying the different elements of service offered, as well as the hierarchy of these elements according to their contributions to overall satisfaction. We try to better understand the impact of improving each element on the increase in satisfaction.

The questions that challenged us are the following:

$>$ What are the dimensions of the service that seem particularly priority for Air Algeria customers?

$>$ What is the degree of customer satisfaction with the various Air Algeria services?

$>$ Does improving each element of service equally contribute to increasing the level of satisfaction?

$>$ What actions should be taken to optimize Air Algeria customer satisfaction? 
Our main goal is to increase customer satisfaction. This objective can be broken down into four subobjectives, namely: the identification of the dimensions of the service considered as priorities for the customers, the measurement of the degree of customer satisfaction with the services offered, the determination of the actions to be taken to improve customer satisfaction, with the aim of securing their loyalty and this in order to determine the impact of the improvement of each dimension on the increase in the degree of satisfaction and loyalty of AIR ALGERIE customers.

In order to shed more light on these questions, we have made two hypotheses, which are as follows:

$\mathrm{H1}$ : The customer does not derive satisfaction from the service itself, but from each element that makes it up.

$\mathrm{H} 2$ : the qualitative improvement of each of the elements of the service influences differently the increase in the degree of satisfaction.

To confirm or refute these hypotheses, we carried out an empirical study with customers of the airline company "AIR ALGERIE". This study affected a sample of 242 customers who made at least four trips with this company. We therefore had recourse to the attribute selection methods where we used the "WEKA" programming environment. The attributes classified by the different algorithms represent the thirteen elements of the service determined in our study.

\section{CONCEPTUAL FRAMEWORK FOR RESEARCH}

Lancaster (1966) was the first to model the importance of characteristics in customer satisfaction. He insists that customers derive satisfaction not from the good as such but from the characteristics possessed by the good. In the approach proposed by Lancaster, agents make choices in the space of characteristics and no longer in the space of goods, given their preferences. Overall satisfaction arises from the sum of elementary satisfactions (Poubanne, 2003). The improvement of each element of service affects the level of satisfaction differently. Given the importance of 'Satisfaction' in this research, it deserves special attention.

\subsection{Satisfaction}

The end point of the business / customer relationship depends essentially on meeting customer needs, which is the very purpose of the marketing process. It expresses the degree of contentment provided by the response to a need or a desire. This satisfaction influences the subsequent behavior of the customer, namely: repurchase, positive word-of-mouth, loyalty (Le Golan, 1998).

Several definitions have been attributed to the notion of "satisfaction", it has been the subject of research for more than thirty years in marketing (Evrard, 1993). But all reflect the same research: to satisfy the consumer in all his requirements, those he formalizes, but also those that he does not think about or that 


\section{INTELLIGENT HIERARCHIZATION OF SERVICE ELEMENTS CONTRIBUTING TO OVERALL CUSTOMER SATISFACTION “ CASE OF AIR ALGERIE CUSTOMERS "}

he cannot express, but which will constitute the little extra that will make a customer satisfied. Whatever definition is adopted, it leads the company to measure the way in which the customer evaluates the level of his state of contentment when using the product or service.

Daniel Ray, (2001) indicates that "satisfaction is the impression of being suitably or not rewarded for the sacrifices incurred during a purchasing situation ", for Llosa (1996) satisfaction represents" an evaluation that occurs after the purchase, use, consumption or experimentation of a product or service ". This means that there will be satisfaction only if the service provided exactly what the consumer wanted. Add to this that satisfaction is based on perceptions and expectations.

\subsubsection{The characteristics of satisfaction}

Three fundamental characteristics of satisfaction are generally recognized in the literature; to know

$>$ His subjectivity: satisfaction depends on the customer's perception of the product or service and not on reality.

> Its relativity: Satisfaction varies from one customer to another depending on the level of the different expectations, that is to say (it depends on the expectations of the customer).

- His evolution: As a rule, satisfaction evolves over time according to customer expectations.

These characteristics all participate in forming the judgment of a client who evaluates a service. The judgment of the customer of a service is not based on absolute bases but is built in a subjective, relative and evolutionary way. For the same service experience, the degree of satisfaction experienced by individuals will inevitably be different.

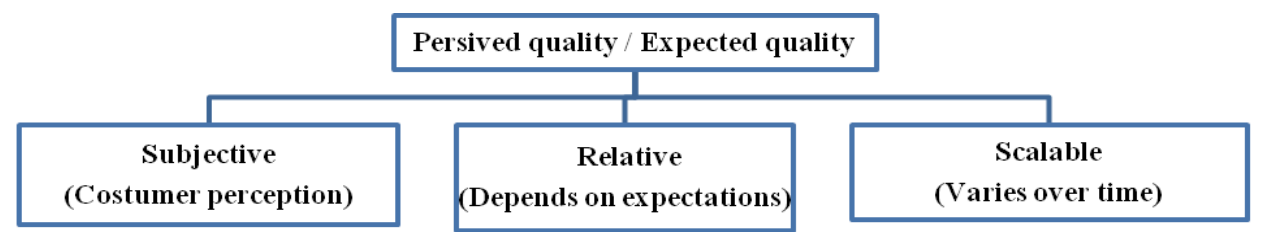

FIGURE 1: CHARACTERISTICS OF A CLIENT'S JUDGMENT FORMATION

Source: Daniel Ray, Measuring and developing customer satisfaction, edition of Organization, Paris, 2001, p24.

\subsubsection{Satisfaction assessment}

Satisfaction is a measurable concept once its criteria have been identified by the company. Its measurement is a feedback operation which consists in knowing the opinion of customers through their needs, their expectations, and their experiences with regard to the services or products received, also allowing companies to check to what extent they improve customer satisfaction. their clients. We measure satisfaction in order to know the customer's point of view on its products or services in order to both identify weaknesses and try to remedy them (Eiglier \& Lingard, 1987). To operationalize and 
measure the concept of "satisfaction" two approaches are cited in the literature, namely: the global approach and the multi-item approach (Zeithaml et al., 1990).

Operationalization according to the global approach (with a single item)

> This approach suggests measuring customer satisfaction with the product or service in a holistic way. The most common measure is to ask customers to indicate their level of satisfaction on a Likert-type scale ranging from "Very dissatisfied" to "Very satisfied". However, there are several variations on this scale, for example, the percentage scale where 100\% indicates a "Completely Satisfied" customer and $0 \%$ indicates a "Very dissatisfied" customer.

$>$ Operationalization according to the multi-item approach

> The most widely adopted approach, it consists of breaking down the product or service into various attributes or elements. The degree of customer satisfaction is then obtained by combining the degrees of satisfaction with each of these attributes. Taking the example of a hotel service. The latter is broken down into several attributes such as the quality of reception, the quality of the meal served, the comfort of the mattresses, the cleanliness of the rooms and of the linen, etc. The customer rates each attribute separately and indicates their level of satisfaction with each item. The customer's score is obtained by calculating the sum or the average of his evaluations. Sometimes respondents are asked to indicate the importance given to different elements. In this case, the customer satisfaction score is calculated by the sum or the weighted average, in order to take into account the fact that the different attributes of a product or a service do not all have the same importance in the eyes of the client (Churchill and Surprenant, 1982)

> Several authors like Vavra (1997) and Hill \& Alexander (2000), recommend the use of customer satisfaction measures operationalized according to the multi-item approach, given the advantage that they have over measures resulting from the global approach. They allow the identification of elements judged to be satisfactory by customers. These measures have been used by other researchers, notably, Danaher \& Haddrell (1996), Danaher (1997), Page \& Spreng (2002), Chu (2002), Busacca \& Padula (2005).

Remember that most models offer a linear representation of the impact of service elements on satisfaction. However, for some researchers the impact would not always be linear, there may be an "asymmetry" relationship. Asymmetry in the field of measuring satisfaction, is a theory that claims that the elements of service contribute differently on overall satisfaction. Certain elements have an impact on satisfaction without influencing dissatisfaction. But that does not prevent certain elements from influencing both satisfaction and dissatisfaction. Asymmetric models determine the assessment of the contribution of elements of a service experience to customer satisfaction. As they serve both to prioritize service elements and to identify investment priorities. Several approaches have been 
Chikh Kadri D., Chib, D.A., \& Brahimi, A.

INTELLIGENT HIERARCHIZATION OF SERVICE ELEMENTS CONTRIBUTING TO OVERALL CUSTOMER SATISFACTION “ CASE OF AIR ALGERIE CUSTOMERS "

adopted for the hierarchization of the elements of services, we have opted for the methods of selection of the attributes for their total independence of the classifier used.

\section{ATTRIBUTE SELECTION METHODS}

In recent years, the selection of attributes has become a very active research subject in several fields such as machine learning, data mining, etc. When it comes to data on customer satisfaction in service marketing, the selection of attributes serves a dual purpose. On the one hand, the identification of dimensions or service elements has an impact on overall satisfaction, on the other hand, the determination of the most relevant and priority dimensions in the improvement process, with the aim of increasing customer satisfaction, eliminating attributes of weak influence.

Attribute selection consists of choosing from a set of large attributes a subset of attributes relevant to a given application. The main motivations behind this choice are as follows:

- Improve overall satisfaction by eliminating attributes with unnecessary information.

- Achieve a better generalization of data by avoiding over-learning.

- Reduce learning and execution time, which results in less expensive learning in terms of computational complexity.

\subsection{Principles of selecting and extracting variables}

These methods make it possible to make the set of data more representative of the problem and to reduce, not only, the storage space required for this data, but also the time for learning and using the processing models. There are two approaches to dimension reduction, namely: extracting variables and selecting variables.

$>$ Variable extraction methods

They consist in transforming the set of starting variables into a new set of variables, generally smaller, while keeping as much as possible the original structure of the data. Among these methods, we mainly mention Principal Component Analysis (PCA) and Discriminant Factor Analysis (DFA). These methods allow the conservation of information related to variables. However, they suffer from major drawbacks, such as excessive consumption of computation time and the absence of an explanation of the variables extracted semantically. 


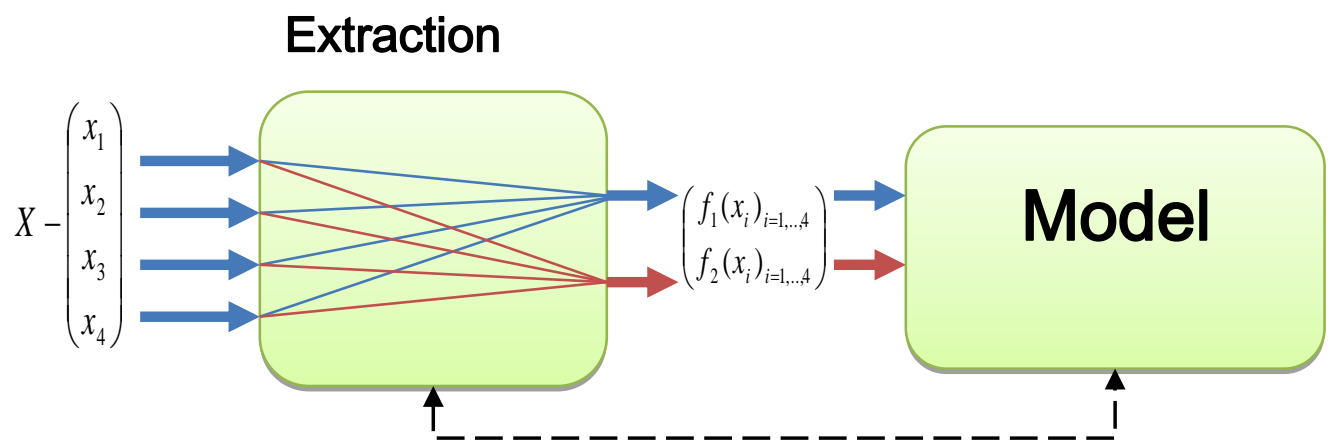

FIGURE 2: PRINCIPLE OF VARIABLE EXTRACTION

Source: Guérif and Bennani (2007)

Variable selection methods

These methods make it possible to choose a relevant subset of variables from the original set and this according to a performance criterion. These methods allow faster characterization of data. The selection of variables does not modify the original representation of the data: the selected variables keep their initial semantics and can then be interpreted more easily by the user.

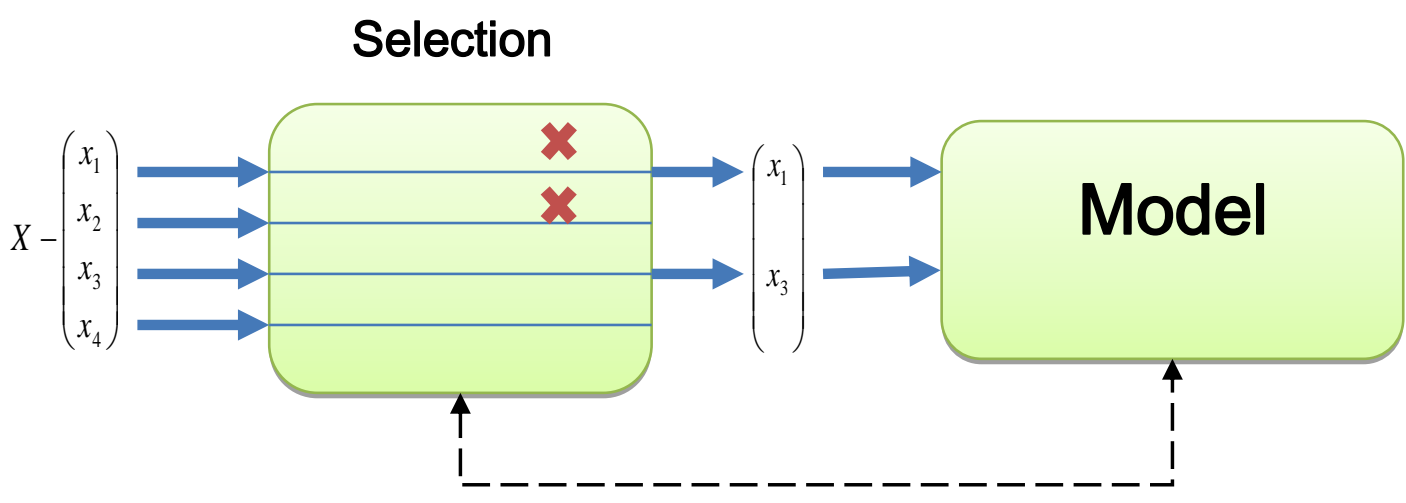

FIGURE 3: PRINCIPLE OF VARIABLE SELECTION

Source: Guérif and Bennani (2007)

\subsection{Attribute selection procedures}

Attribute selection algorithms can be divided into two categories:

Attribute Ranking Algorithms (FEATURE-RANKING) also known under the name of the UNIVARIOUS FILTER, consist in ordering the set of starting attributes according to an evaluation criterion and then selecting the most relevant attributes with respect to the criterion used. 


\section{INTELLIGENT HIERARCHIZATION OF SERVICE ELEMENTS CONTRIBUTING TO OVERALL CUSTOMER SATISFACTION “ CASE OF AIR ALGERIE CUSTOMERS "}

$>\quad$ Subset search algorithms (SUBSET-SELECTION) also known under the name MULTI VARIETY FILTER, they search for the most relevant subset of attributes according to a certain selection criterion. These algorithms must then find the best subset of attributes among all the candidate subsets.

\section{EMPIRICAL FRAMEWORK FOR RESEARCH}

Our empirical study is carried out in the context of services, more precisely in air transport. This sector of activity does not only offer transport to customers, but also other services, namely: smooth check-in, information in the event of delay, seat comfort, handling of baggage disputes, etc. The diversity of services proposed, and criteria involved in customer satisfaction, led us to select this field of application to measure the importance of service elements in customer satisfaction.

\subsection{Data gathering and administration of the questionnaire}

The study was carried out with a sample made up of 242 customers of the AIR ALGERIE company,

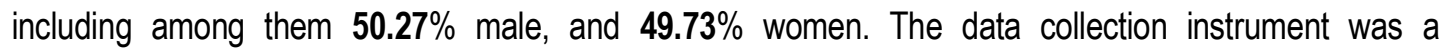
questionnaire to be completed by the clients of this last. This questionnaire is composed of 13 service elements, of which customers are asked to express their degree of satisfaction or dissatisfaction on a Likert scale comprising 5 points.

\subsubsection{Data collection}

The data collection was carried out in two stages: a qualitative stage followed by a second quantitative stage. The qualitative stage was intended to methodically collect the elements of service contributing to the overall satisfaction of the company's customers. Semi-structured interviews were carried out with colleagues and people who have already made at least four trips with AIR ALGERIE. During this phase, nine service elements were selected, namely: the price of the ticket, punctuality, reception, comfort on board the plane, baggage handling, quality of the meal tray, the waiting time, the nature of the aircraft and the weight of the baggage.

After testing our questionnaire with around fifty customers, other attributes appeared (revelation of many respondents), namely the quantity, the credibility of the information provided, the speed of the service. on board as well as the safety felt on board the aircraft, in other words 'pilot qualification'. The elements of service that we selected for this study are presented in table 1:

TABLE1: DESCRIPTION OF THE SERVICE ELEMENTS

\begin{tabular}{|l|l|}
\hline ELEMENT & DESCRIPTION \\
\hline X1 & Plane ticket \\
\hline X2 & Punctuality \\
\hline X3 & Amount of information provided \\
\hline X4 & Credibility of the Information provided \\
\hline X5 & Home \\
\hline
\end{tabular}




\begin{tabular}{|l|l|}
\hline X6 & Comfort on board the plane \\
\hline X7 & Baggage handling \\
\hline X8 & Confidence and Safety inspired by the crew \\
\hline X9 & Speed of service on board the plane \\
\hline X10 & Quality of the meal tray \\
\hline X11 & Waiting time \\
\hline X12 & Nature of the plane \\
\hline X13 & Luggage weight \\
\hline
\end{tabular}

Source: author

\subsubsection{Development of the questionnaire}

The internet, which is now a ubiquitous technology in our daily lives, we have used it as a means to obtain a larger and more varied population in terms of geographical distribution, intellectual level and age. We therefore opted for an electronic version of our questionnaire, carried out through a Google application called "Google Form"; the latter generates an HTTP link. We have shared it in different ways, namely e-mails or rather via social networks such as Facebook or Tweeter. This electronic version allowed us to collect more information and more quickly. These data are available on the same interface which further facilitates their processing and handling.

\subsection{Results of the hierarchization of service elements}

We have chosen the hierarchization by the methods of selection of the attributes with the approach of type " FILTER " given the interest represented by these models in this field. We used the WEKA source OPEN software to obtain the subsets of attributes. The evaluation function is used to measure either:

- The relevance of attributes by appreciating them individually, when using a selection algorithm by ranking attributes (univariate filter)

- The relevance of the subsets of attributes generated by one of the different generation methods, when using a subset search algorithm (multivariate filter)

Remember at the beginning, that the attributes classified by different algorithms represent the elements of the service that contribute to overall satisfaction.

\subsubsection{Univariate filter}

In this type of approach, single attribute evaluators are used with the "Ranker" search method to generate a ranked list of attributes according to a specific score. This score is calculated according to a predefined evaluation method. We will define in what follows, the three types of evaluators as well as the classification of the attributes " elements of service " retained.

The InfoGainAttributEval algorithm evaluates the value of an attribute by measuring the information gain relative to the class. The information gain (also called "Kullback-Leibler divergence" or "relative entropy") is a measure of the dissimilarity between two laws of probability. 
Infogain (class, attribute $)=H$ (Class) $-H$ (Class $\mid$ Attribute)

Therefore, the information gain measures the efficiency of an attribute $A$ with the reduction in entropy. To calculate the entropy E:

Let $\mathrm{S}$ be the set of examples. Let us suppose that the attribute to be predicted takes $\mathrm{M}$ distinct values defining $M$ classes $C 1 \ldots, C M$. The entropy $E(S)$ is defined by:

$E(S)=-\sum_{i=1}^{M} p_{i} \log _{2} p_{i}$

Where Pi denotes the proportion of examples of $\mathrm{S}$ belonging to $\mathrm{Ci}$

From the entropy, we can calculate InfoGain:

$\operatorname{InfoGain}(S, A)=E(S)-\sum_{k}^{k=m} \frac{\left|S_{k}\right|}{|S|} E\left(S_{k}\right)$

Where $A$ takes the values $a 1, . .$, am And $S k$ is the subset of $S$ for which the attribute $A$ takes the value Ak. Table 02: represents the information gain score of the 13 best attributes according to the calculation obtained during the learning phase by applying the InfoGain filter calculated by the above formulas.

TABLE 2: SCORE OF THE BEST ATTRIBUTES ACCORDING TO INFOGAINATTREVAL

\begin{tabular}{|l|l|}
\hline Attribute No. & InfoGain \\
\hline $\mathbf{5}$ & 0.455 \\
\hline $\mathbf{2}$ & 0.452 \\
\hline $\mathbf{1}$ & 0.428 \\
\hline $\mathbf{8}$ & 0.419 \\
\hline $\mathbf{7}$ & 0.416 \\
\hline $\mathbf{1 1}$ & 0.409 \\
\hline 12 & 0.365 \\
\hline 4 & 0.339 \\
\hline 13 & 0.309 \\
\hline 9 & 0.303 \\
\hline 10 & 0.300 \\
\hline 6 & 0.287 \\
\hline 3 & 0.261 \\
\hline & Source: author \\
\hline
\end{tabular}

The values in the second column correspond to the weight given to each dimension. These values allow prioritization from the element with the highest weight to the lowest. By focusing on the first six elements, using this approach, we have chosen the following order: welcome, punctuality, ticket price, confidence and security inspired by the on-board staff, handling of luggage and confidence and time expectations. 
We have in last position; the quality of the meal tray followed by the comfort on board the aircraft and finally the quantity of information provided with a low weighting indicating a low contribution to overall satisfaction.

\section{Gain Ratio Algorithm}

The Gain Ratio Attribute Eval algorithm evaluates the value of an attribute by measuring the ratio of the gain to the class.

GainRatio (class, attribute $)=(\mathrm{H}$ (Class) $-\mathrm{H}$ (Class | Attribute) $) / \mathrm{H}$ (Attribute) .

By introducing partitioning information, Gain Ration adjusts InfoGain with the entropy of the partitioning. We have the possibility to calculate it with the following formulas:

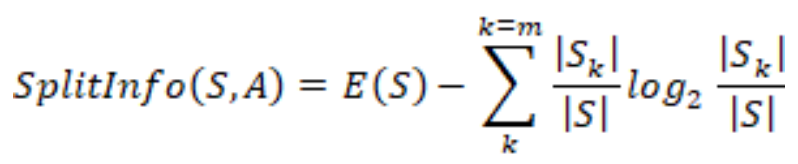

$$
\operatorname{GainRatio}(S, A)=\frac{\operatorname{InfoGain}(S, A)}{\operatorname{SplitInfo}(S, A)}
$$

The scores obtained for the 13 best attributes according to GainRatio are represented in table 03:

TABLE 03: TOP ATTRIBUTE SCORES USING GAINRATI
\begin{tabular}{|c|l|}
\hline ATTRIBUTE NUMBER & INFOGAIN \\
\hline $\mathbf{1}$ & 0.218 \\
\hline $\mathbf{2}$ & 0.214 \\
\hline $\mathbf{5}$ & 0.211 \\
\hline $\mathbf{1 1}$ & 0.207 \\
\hline $\mathbf{8}$ & 0.205 \\
\hline $\mathbf{7}$ & 0.201 \\
\hline 12 & 0.168 \\
\hline 9 & 0.164 \\
\hline 4 & 0.163 \\
\hline 13 & 0.153 \\
\hline 6 & 0.148 \\
\hline 10 & 0.136 \\
\hline 3 & 0.132 \\
\hline &
\end{tabular}

Source: author

The second column contains the weights given to each element allowing the hierarchy, starting from the one with the greatest weighting to the one with the lowest weighting. By considering the first six elements, according to this approach, we retain the following order: ticket price, punctuality, reception, waiting times, 
Chikh Kadri D., Chib, D.A., \& Brahimi, A.

INTELLIGENT HIERARCHIZATION OF SERVICE ELEMENTS CONTRIBUTING TO OVERALL CUSTOMER SATISFACTION “ CASE OF AIR ALGERIE CUSTOMERS "

the confidence and security inspired by the staff on board and the handling of luggage. We have in last position; the comfort on board the plane, the quality of the meal tray and finally the quantity of information provided with a low weighting indicating a low contribution to overall satisfaction.

$>$ Chi2 algorithm

The Chi Squared Attribute Eval algorithm evaluates attributes by estimating, using a chi2 test, the association between the attribute and a given class. The Chi 2 test (Chi 2 or) proposed by the statistician Karl Pearson in 1900, makes it possible to determine the probability that the rows and columns of a crosstab are independent. It means that $\mathrm{X} 2$ :

- The fact of belonging to one of the modalities of the first variable has no influence on the modality of belonging of the second.

- The row percentages of the crosstab are the same for all rows.

- The column percentages of the crosstab are the same for all columns.

The test is based on the value of the table, which is a measure of the difference between the observed table and the table that would have been obtained if the variables were perfectly independent, and on the number of degrees of freedom of the table, which depends on the number of rows and columns. The results obtained are presented in Table 04:

TABLE 04: SCORE THE BEST ATTRIBUTES USING CHI2
\begin{tabular}{|l|l|}
\hline ATTRIBUTE NUMBER & INFOGAIN \\
\hline $\mathbf{5}$ & 327.8893 \\
\hline $\mathbf{1}$ & 269.9519 \\
\hline $\mathbf{2}$ & 188.6185 \\
\hline $\mathbf{7}$ & 159.1433 \\
\hline $\mathbf{6}$ & 159.0834 \\
\hline $\mathbf{8}$ & 142.3108 \\
\hline 11 & 130.4669 \\
\hline 12 & 122.0946 \\
\hline 13 & 112.6621 \\
\hline 4 & 105.8867 \\
\hline 10 & 89.2581 \\
\hline 9 & 84.9265 \\
\hline$€ 3$ & 73.8915 \\
\hline & Source: author \\
\hline
\end{tabular}

The values in the second column correspond to the weight given to each dimension. By focusing on the first six elements, we have chosen the following order according to this approach: reception, ticket price, punctuality, baggage handling, comfort on board the plane, the confidence and security inspired by the staff from the edge. We have in last position; the quality of the meal tray followed by the speed of the 
service and finally the quantity of information provided with a low weighting indicating a low contribution to the overall satisfaction.

\subsection{Multivariate filter}

In this type of approach, we take a subset of attributes that refers to a numerical measure that guides the search, we used a CFS type filter. The CFSSubsetEval filter evaluates the predictive ability of each attribute individually and the degree of redundancy between them, preferring sets of attributes that are highly correlated with class, but with low cross-correlation. An option iteratively adds the attributes that have the strongest correlation with the class, provided that the set does not already contain an attribute that has an even higher correlation with the attribute in question. The search algorithms traverse the attribute space to find a good subset, for these two methods are used, namely:

- BestFirst algorithm

The BestFirst algorithm searches the space of attribute subsets by glutton escalation (GreedyHill Climbing) with a rollback center. The main idea is to use an evaluation function to estimate the interest of the nodes and develop the most interesting node. The node to be developed is chosen according to an evaluation function and the cost of the shortest path to reach the goal is estimated by a heuristic function. Best-First can start with the empty set of attributes and forward search, or start with the full set of attributes and backward search, or start anytime and search both directions (taking into account all possible additions and deletions of unique attributes at any given time).

The BestFirst algorithm retained the following 9 attributes: 1,2,5,7,8,9,11,12,13

- Random Algorithm

This algorithm performs a random search in the space of subsets of attributes. If no start setting is provided, the random search starts from a random point and reports the best subset found. If a starter set is provided, random searches are performed for subsets that are as good or better than the starting point with the same number of attributes or less. Using RandomSearch in conjunction with a Starter Set Contains All Attributes is equivalent to Liu and Setiono's (1996) LVF algorithm.

The random search algorithm retained the following 8 attributes: 1,2,5,7,8,11,12,13.

\section{DISCUSSIONS OF THE RESULTS}

The objective of this study is to identify the relevant service elements involved in overall satisfaction. To this end, we used the FILTER method with two different approaches of the 'univariate' and 'multivariate' type. We then compared the results obtained which are presented as follows: 
Chikh Kadri D., Chib, D.A., \& Brahimi, A.

\section{INTELLIGENT HIERARCHIZATION OF SERVICE ELEMENTS CONTRIBUTING TO OVERALL CUSTOMER SATISFACTION “ CASE OF AIR ALGERIE CUSTOMERS "}

For the Univariate Filter method: it seemed useful to us to start with the Information Gain which measures the efficiency of an attribute with the reduction in entropy. The results obtained by InfoGainAttrEval follow this order: $5,2,1,8,7,11,12,4,13,9,10,6,3$. Whereas, the best scores obtained after using the GainRatioAttributeEval which evaluates the value of an attribute by measuring the ratio of gain to the class, are as follows: $1,2,5,11,8,7,12,9,4,13,6,10.3$. Finally, the Chi2 approach by the algorithmChiSquaredAttributeEval which evaluates the attributes by estimating the association between the attribute and a given class offers us the hierarchy of the following dimensions: $5,1,2,7,6,8,11,12,13,4,10,9,3$.

Regarding the Multivariate method, or U.Swe limit to the use of a CFS type filter, which evaluates the predictive capacity of each attribute individually and the degree of redundancy between them. According to this approach, attribute sets are highly correlated with class, but those with low inter-correlation are best. Two different search algorithms are used; best-first and random, we present the results obtained as follows:

Regarding the BestFirst algorithm, retained 9 attributes hierarchized as follows: 1,2,5,7,8,9,11,12,13. For the random search algorithm, it retained 8 order attributes: 1,2,5,7,8,11,12,13.

Based on the results obtained, we can notice a great similarity between the hierarchical attributes. If we focus on the following six elements of service: ticket price (X1), punctuality $(X 2)$, welcome $(X 5)$, baggage handling (X7), trust and security inspired by the personnel on board (X8) and the waiting time (X11), we observe that they continue in the five approaches used, except for the Chi2 method where we notice the deviation of $\mathrm{X} 11$ and the introduction of X6 ( the comfortable on board the plane).

We can deduce that the six elements of service mentioned above are those that most influence the overall satisfaction of AIR ALGERIE's customer, to varying degrees. But we also found that the reported weight difference between the following dimensions in the set of methods used is minimal. This explains and reinforces the idea that they are priorities in the improvement process that this company must take in order to increase the degree of satisfaction of its customers in order to retain them. While there is no need to suggest improvements in the media, for the service dimensions that have been classified in denier, such as: the speed of the service on board the plane, the quality of the meal tray, the weight of the luggage and the nature of the aircraft, since they do not intervene in the overall satisfaction,

We were able to confirm our two hypotheses through the study carried out on the hierarchization of the dimensions of service offered by AIR ALGERIE. We have indeed observed with regard to the first hypothesis, that the customer of this company evaluates his state of satisfaction after a comparison made between his perceptions and his expectations for each element composing the service, to express at the end his satisfaction or his overall dissatisfaction. Whereas for the second hypothesis and according to the 
results obtained, we have observed that the various elements of service considered in our study do not have the same degree of influence on the overall satisfaction of the customer. This hypothesis was justified by the results of the classification of these elements based on the five selection methods. We were able to deduce that the first six dimensions selected are the same except that a slight nuance exists between them, which explains why they have a more or less strong impact on overall satisfaction. This helps us to confirm that the qualitative improvement of each dimension of the service has a different influence on the increase in the degree of satisfaction and that the improvement of each of them has a different effect on satisfaction.

Regarding the "Ticket price: X1" element, we recorded a rate of $28 \%$ of customers very dissatisfied with the price of the ticket, $33.52 \%$ are dissatisfied, $10.71 \%$ are indifferent, the 19 th , $43 \%$ are satisfied, and the $8.34 \%$ are very satisfied, executives are expected to offer studied ticket prices by aligning with competitors. The increase in ticket prices with the poor state of the economy will result in severe losses for the company. It is recognized that price is a major determinant in the company selection process. It should be noted here that, business customers are less sensitive to ticket prices because they do not pay for it, in our sample we have $39.3 \%$ of customers travel for business reasons.

The second element influencing overall satisfaction is "Punctuality: X2", the statistical results obtained are as follows: the $35.72 \%$ are very dissatisfied, the $34.52 \%$ are dissatisfied, the $10.71 \%$ are indifferent, the $13.10 \%$ are satisfied and the $5.95 \%$ considered very satisfied. It should be noted here that travellers are used to flight delays, but it remains an annoying phenomenon for all AIR ALGERIE customers which must be resolved, not to offer compensation for delays but to reduce or avoid it altogether. In the 1990s, an American airline, Southwest, made its mark with its service based on punctuality, baggage handling and customer satisfaction (Robinson \& Paré, 2007).

In third position we cite "Accueil: X5", which indicates the importance of this dimension and which encourages those in charge to take a close interest in it. It is classified among the elements having a strong impact on overall satisfaction. The statistical results of this element gave the following values: the rate of very dissatisfied customers is $25 \%$, that of dissatisfied customers is $16.67 \%$, the rate of indifferent customers is equal to $15.47 \%$, the satisfied represents a rate of $34.52 \%$ and $8.34 \%$ are considered very satisfied. The client of AIR ALGERIE noticed that the quality of the reception was lower than he expected. The fourth dimension judged by the sample is "Baggage handling: X7".Its statistical results regarding satisfaction were as follows: $17.86 \%$ of customers are very dissatisfied, $25 \%$ are dissatisfied, $22.62 \%$ are indifferent, $28.57 \%$ are satisfied and only $5.95 \%$ are very satisfied. The most inconvenient at the end of the trip is seeing the damaged suitcases.

For the fifth dimension which seems important for the client of AIR ALGERIE is the "Confidence and Safety Inspired by the On-Board Personnel: X8", it is about the qualification of the pilots. Remember that 
Chikh Kadri D., Chib, D.A., \& Brahimi, A.

\section{INTELLIGENT HIERARCHIZATION OF SERVICE ELEMENTS CONTRIBUTING TO OVERALL CUSTOMER SATISFACTION “ CASE OF AIR ALGERIE CUSTOMERS "}

this dimension was added after the test of our questionnaire. By answering the following question: Can you specify what you appreciated the most about the AIR ALGERIE company? The $32.56 \%$ of the questioned appreciated: the qualification of the pilots, the quality of their landings, the safety felt with them... etc, all these answers refer to the same idea, that they are reassured with the pilots of this company. For the statistical results of all customers, we have $10.71 \%$ of them are very dissatisfied, $16.67 \%$ are dissatisfied, $19.05 \%$ are indifferent, $36.90 \%$ are dissatisfied and $16.67 \%$ are very satisfied.

In a lower level we cite "comfort on board the plane (X6)". Our statistical results were as follows: $19.15 \%$ of clients are very dissatisfied, $22.22 \%$ are dissatisfied, $20.64 \%$ are indifferent, $27.38 \%$ are satisfied and $10.61 \%$ are very satisfied. Air travel is arduous and can take hours of flying, a comfortable seat, and anything the customer wants. Regarding the remaining dimensions, we recall that information management has always been a particularly strategic element for companies working in the tourism sector in general and air transport. The possession use and possibly retention of information have become key issues for the company and its strategy, whether it is towards employees (internally) or towards customers and other stakeholders outside the company (external level). The holding of information appears to be the centrepiece in the tourism sector. The World Tourism Organization believes that "travellers must be informed as accurately, honestly and as often as possible about the situation of world tourism and its dangers". In the airline industry, Fiorino (1999) believes that passengers want to hear honest information from those responsible, especially regarding a flight delay.

\section{CONCLUSION}

Our research focused on the elements of service and their contribution to overall customer satisfaction. The answer to our initial problematic required the determination of certain elements of services which seem to influence the overall satisfaction of the customers.

We concluded that the selection of variables has always attracted a lot of interest in the literature. We have presented a new criterion allowing the evaluation of the relevance of a subset of variables. The proposed criterion can be associated with any discriminator. Tests carried out on a real data set have shown that the proposed criterion is able to select the relevant variables and, in most cases, to increase the rates of good prediction. We validated these proposed variable selection methods on a real prediction problem.

The application of the attribute selection method concerns an automatic prediction system of the overall satisfaction of Air-Algeria's customers. We carried out a comparative experimental study with a particular interest in "FILTER" type methods for their total independence from the classifier used. We notice that the MULTIVARIE type methods have more advantages for considering interactions between service 
dimensions. The selection of the various service elements made it possible to know in an explicit and intelligent way the real opinion of the customer of this national air transport company. We have found that the dimensions having an impact on overall satisfaction continue in a different way but close to each other, the gap between the service elements is minimal. What led us to identify the dimensions having a strong impact on overall satisfaction, which must be a priority in the improvement process, namely: reception, punctuality, ticket price, inspired confidence and safety at on board, baggage handling comfort on board the plane, waiting time and baggage weight, the other dimensions have little influence. But we were also able to have the service dimensions having a weak influence such as: the speed of the service on board the plane, the quality of the meal tray, the weight of the luggage and the nature of the plane, which were classified in However, there is no need to suggest improvements in the media since they do not intervene in the overall satisfaction. What led us to identify the dimensions having a strong impact on overall satisfaction, which must be a priority in the improvement process, namely: reception, punctuality, ticket price, inspired confidence and safety at on board, baggage handling comfort on board the plane, waiting time and baggage weight, the other dimensions have little influence. But we were also able to have the service dimensions having a weak influence such as: the speed of the service on board the plane, the quality of the meal tray, the weight of the luggage and the nature of the plane, which were classified in However, there is no need to suggest improvements in the media since they do not intervene in the overall satisfaction. What led us to identify the dimensions having a strong impact on overall satisfaction, which must be a priority in the improvement process, namely: reception, punctuality, ticket price, inspired confidence and safety at on board, baggage handling comfort on board the plane, waiting time and baggage weight, the other dimensions have little influence. But we were also able to have the service dimensions having a weak influence such as: the speed of the service on board the plane, the quality of the meal tray, the weight of the luggage and the nature of the plane, which were classified in However, there is no need to suggest improvements in the media since they do not intervene in the overall satisfaction.

We point out at the end of this study that behind the overall satisfaction of Air Algeria's customers, several service dimensions. This will certainly allow this company to provide a double effort to bring real and effective improvements as well as to give more care to the relevant variables selected by the different methods applied in our research work. The experimental results obtained have shown us the interest as well as the need to use formalized methods and so-called automated or intelligent approaches for the analysis of ground truth data. 


\section{INTELLIGENT HIERARCHIZATION OF SERVICE ELEMENTS CONTRIBUTING TO OVERALL CUSTOMER SATISFACTION “ CASE OF AIR ALGERIE CUSTOMERS "}

\section{REFERENCES}

Busacca, B., \& Padula, G. (2005). Understanding the relationship between attribute performance and overall satisfaction: Theory, measurement and implications. Marketing Intelligence \& Planning.

Chu, R. (2002). Stated-importance versus derived-importance customer satisfaction measurement. Journal of Services Marketing.

Churchill Jr, G. A., \& Surprenant, C. (1982). An investigation into the determinants of customer satisfaction. Journal of marketing research, 19(4), 491-504.

Danaher, P. J. (1997). Using conjoint analysis to determine the relative importance of service attributes measured in customer satisfaction surveys. Journal of retailing, 73(2), 235-260.

Danaher, P. J., \& Haddrell, V. (1996). A comparison of question scales used for measuring customer satisfaction. International Journal of Service Industry Management.

Eiglier, P., \& Langeard, E. (1987). Servuction, le marketing des services, éditions Mc GrawHill.

Évrard, Y. (1993). La satisfaction des consommateurs: état des recherches. Revue française du marketing, (144), 53-66.

Fiorino, F. (1999). Seating situation is root of much passenger discontent. Aviation Week and Space Technology, October, 62-65

Guérif, S., \& Bennani, Y. (2007, August). Dimensionality reduction trough unsupervised features selection. In International Conference on Engineering Applications of Neural Networks.

Hill, N., \& Alexander, J. (2000). Handbook of customer satisfaction and loyalty measurement. Gower Publishing, Ltd..

Honomichl, J. (1993). PR about research that pays can also pay off for researchers. Marketing News, 27(19), 31-31.

Keith, R. J. (1960). The marketing revolution. Journal of marketing, 24(3), 35-38.

Lancaster, K. J. (1966). A new approach to consumer theory. Journal of political economy, 74(2), 132 157.

Le Golan, Y. (1998). Marketing dictionary, Dunad Edition, Paris.

Liu, H., \& Setiono, R. (1996, July). A probabilistic approach to feature selection-a filter solution. In ICML (Vol. 96, pp. 319-327).

Llosa, S. (1996). Contributions à l'étude de la satisfaction dans les services (Doctoral dissertation, AixMarseille 3).

Mittal, V., \& Kamakura, W. A. (2001). Satisfaction, repurchase intent, and repurchase behavior: Investigating the moderating effect of customer characteristics. Journal of marketing research, 38(1), 131-142.

Page Jr, T. J., \& Spreng, R. A. (2002). Difference scores versus direct effects in service quality measurement. Journal of service research, 4(3), 184-192.

Popescu, R., Corbos, R. A., Comănescu, M., \& Bunea, O. I. (2017). Ecological Marketing-Strategic Option for Business Development in Bucharest. ECONOMIC COMPUTATION AND ECONOMIC CYBERNETICS STUDIES AND RESEARCH, 51(2), 67-83.

Poubanne, Y. (2003). Relation directe entre la performance perçue et la fidélité $d u$ consommateur (Doctoral dissertation, Aix-Marseille 3).

Ray, D. (2001). Measuring and developing customer satisfaction, edition of Organization, Paris. 
Robinson, F., and Paré, M. (2007), Client approach management, Editions de la Chenelière, gaëtanmorin editor.

Vavra, T. G. (1997). Improving your measurement of customer satisfaction: A guide to creating, conducting, analyzing, and reporting customer satisfaction measurement programs. Quality Press.

Zeithaml, V. A., Parasuraman, A., Berry, L. L., \& Berry, L. L. (1990). Delivering quality service: Balancing customer perceptions and expectations. Simon and Schuster. 